to the smelting of an ore was a great advance, and this discovery was, in all probability, the result of an accident at the edge of a camp fire. The observation by the early workers that copper, as obtained from different deposits, had different properties, led to the mixing of other materials with the copper ore being smelted and ultimately to the production of bronze. It is generally recognised that so early as 3000 B.C., the Egyptians were skilled in the smelting and casting of copper, but the earliest authentic bronzes date from about 1600 B.C.

The next important discovery was the production of iron, and it is generally agreed that iron did not come into general use in Egypt until 1300 B.c., which may be taken as the beginning of the iron age. It appears that the Egyptians were acquainted with the carburising process for converting iron into steel about 1200 B.c., and with the quenching process for hardening steel about 900 B.C. After this, no important metallurgical discovery appears to have been made for a long time. Brass was first made at the beginning of the Christian era, and the next discovery of prime importance was that of cast iron, which was first made in the fourteenth century. This discovery was the outeome of the gradually increasing size of the furnaces used for making direct iron. The smelting of iron ores in large furnaces with the use of coke began early in the eighteenth century and marks the beginning of the modern iron and steel industry.

The next discovery of importance was the making of crucible steel at the end of the eighteenth century, but steel did not become available in large quantities until the invention of the Bessemer process in 1856.
During the last seventy-five years the development has been rapid and during the past thirty years more metal has been used than in all previous time.

Sir Harold Carpenter traced the progress of casting metal from the first castings in stone moulds to the modern methods of centrifugal and pressure die castings. The properties of metals, including strength, ductility and malleability received attention, and the chemical properties, especially as regards their resistance to the chemical action of their environment during service, that is, corrosion, were shown to be of the highest importance.

The effects of science on metallurgy have been most marked and important. So recently as just over a century ago, changes in metallurgical practice were mainly the result of chance discoveries or the consequence of a reaction to changing economic conditions. Scientific attention began to be directed to the systematic search for new alloys, new methods of mechanical and heat treatment, more economical methods of manufacture, better plant and greater reliability of product. The most conspicuous illustration of the influence of science on metallurgy is found in the case of aluminium. It is the most plentifully occurring metal in the earth's crust and yet has become available only within living memory. To-day, iron and aluminium are the two most important metals, iron having been used by man for over three thousand years and aluminium for under fifty years. The application of the methods of science to the ancient art of metallurgy, and the increased know. ledge gained thereby, will contribute ever increasingly to the amenities of human life and the progress of art and industry.

\title{
Spectra of the Planets
}

T HE annual George Darwin lecture was delivered at the Royal Astronomical Society's meeting on May 12; the lecturer being Prof. V. M. Slipher, director of the Lowell Observatory. He chose as his subject the spectra of the planets, the study of which has been, from the first, an important feature in the work of the Lowell Observatory. He noted that the advent of the spectroscope made it possible to learn something about the chemical composition of other worlds, and gave a sketch of the early work carried out by Sir William Huggins, using visual methods.

The introduction of photographic methods made a great advance possible; when the method was first used, the plates employed were insensitive to red light, and the infra-red region was quite excluded. Of late, the makers of plates have triumphed over these difficulties, and a great extent of the infra-red spectrum can now be photographed. This is specially important in planetary work, as there are many interesting lines and bands in this region.

An initial difficulty is that of separating planetary lines from those due to the terrestrial atmosphere. Prof. Slipher described different methods of discrimination; comparing a planet with the moon at the same altitude, or comparing the planet's spectrum at high and low altitudes. Also the terrestrial lines can be weakened by going to a high station. Some photographs have been taken at the San Francisco Peak, $11,000 \mathrm{ft}$. high, which is near the Observatory.
Another method, needing considerable dispersion, makes use of the shift of the planetary lines due to radial motion. This has been applied to Venus, with the result that oxygen cannot bo traced in its spectrum, but carbon dioxide is suspected. Great endeavours were made to test the rotation of Venus by the spectroseope. The slit was placed in various position angles, also with the spectroscope in two opposite positions, $180^{\circ}$ apart; the plates were shuffled, and the measurer kept in ignorance of the conditions of exposure, to prevent any possible bias. Unfortunately, no positive result was reached, but Prof. Slipher considers that ten days might be named as a lower limit to the planet's period of rotation.

Some twenty-five years ago there was a controversy as to the presence of the $a$ band, due to water vapour, in the spectrum of Mars. Lowell's book on the planet, published in 1909, included a reproduction of spectra taken by Prof. Slipher in 1908, showing the $a$ band stronger in the Martian spectrum than in the lunar one. Some doubt was thrown on this by other observers, but the presence of a small amount of water vapour is now generally accepted.

Prof. Slipher then proceeded to discuss the four giant planets; their spectra resemble each other in showing series of conspicuous bands, which increase in strength as we go from Jupiter to Neptune. Spectrograms of Jupiter were shown, which exhibited bands far in the infra-red, to wave-length 10,000 , but 8,600 was 
the limit reached in the case of Uranus and Neptune. The origin of most of these bands is still unknown, but lines due to ammonia have lately been identified in the spectrum of Jupiter; a slide was shown in which they were visible. It is appropriate finding ammonia in Jupiter, as the name is taken from the temple of Jupiter Ammon in Africa, which appears to have been the earliest source of supply of this substance.

Allusion was next made to the determination of the period of rotation of Uranus by spectrograms taken at the Lowell Observatory in 1911. The equivalent focus used was $55 \mathrm{ft}$., and the usual precaution was taken of rotating the spectrograph through $180^{\circ}$, between two series of exposures. The deduced time of rotation was 10.7 hours. Some attempts are being made to see if Pluto shows any periodic variation of light, from which its rotation time can be deduced; but there is nothing as yet to report.
The suggestion, now generally accepted, that the stationary calcium lines in certain stellar spectra are due to light-absorption in interstellar space, not in the stars themselves, was made at the Lowell Observatory in 1909. Prof. Slipher spoke of some faint lines that were photographed on the dark side of Venus, but he is inclined to ascribe them to our own atmosphere. He expressed the opinion that there is a faint permanent aurora present in the atmosphere, and showed some plates taken with long exposures, on which the auroral lines could be traced.

At the conclusion of the lecture, the president, Prof. F. J. M. Stratton, presented the gold medal awarded by the Council to Prof. Slipher for his spectroscopic work on planets and nebulæ. He said that the lecture itself sufficiently established the grounds for the award, and dispensed with the necessity of a presidential address on the subject.

A. C. D. C.

\section{The 'Catkin' Radio Valve}

$\mathrm{W}$

ITH the rapid growth in broadcast reception, the general public has become used to frequent changes in the types and design of receiving valves. These new types have usually been aimed at giving improved performance under modern conditions of radio communication, and in the past, they have invariably appeared in the familiar glass bulb form. A radically different type of construction is adopted in the 'Catkin' valve, which was placed on the market on May 18, by the General Electric Co., Ltd. and the Marconiphone Co., Ltd. This new valve is really a small model of the high-power type of 'Cooled-Anode-Transmitting' (C.A.T.) valve which was produced for wireless transmitting stations a few years ago.

In the new construction shown in the accompanying sectional diagram (Fig. 1), the amount of glass-work, with its fragility and dielectric losses, has been reduced to a minimum. The upper portion of the envelope is formed of the cylindrical copper anode which is sealed to the lower glass portion by a vacuum-tight joint. The other electrodes are rigidly mounted inside this envelope, using mica spacing and insulating pieces where necessary. In the glass type of valve the electrode system is usually carried in the glass 'pinch' near the base, an arrangement which makes it difficult to ensure definite location and gives rise to considerable dielectric losses in some valve circuits. In the new construction, the lower ends of the electrodes are held rigidly in a suitable steel clamp with mica insulation, and the leads are brought out through the glass ring at the base, being well spaced around its circumference. This arrangement makes it possible to obtain much greater precision in the electrode dimensions and spacing in manufacture, so that the mass-produced valves should conform much more accurately to a uniform performance than was possible hitherto.

The glass ring forming the lower portion of the envelope is supported in its base by a rubber clamp, which acts as an efficient sound insulator, thus reducing the susceptibility of the valve to microphonic effects. The much smaller diameter of the anode also results in comparative freedom from response to sound vibrations transmitted through the air, which sometimes form a source of trouble with glass valves.

Screen-grid and detector valves are, nowadays, usually metallised in order to avoid the effects of strong electric fields set up by charges on the glass envelope. The electric field within the anode of the Catkin valve is entirely uninfluenced by any surrounding charges. If further screening is required in order to reduce stray coupling to the anode itself, an octagonal tubular metal cover is provided fitting over the entire valve. In this form the valve is remarkably strong mechanically and its overall dimensions, including the standard four- or five-pin cap, are about 5 in. by $1 \frac{1}{8}$ in. diameter.

Output valves do not require this outer screening

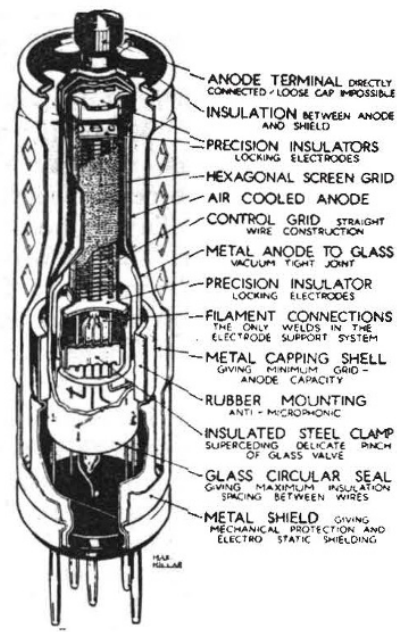

FIG. 1.

cover, and in this case the exposed anode is given a coating of black enamel insulation. In all cases, since the anode is exposed directly to the air, liberal heat-dissipation is provided and the electrode system as a whole runs at a lower temperature, thus reducing the liability of the valve to soften due to the release of gases occluded on the inner walls of the envelope.

The Catkin valve is at present being supplied in four types, the constants of which are similar to those of the corresponding glass valves, so that they are interchangeable with those in use in present-day receivers. 